\title{
TRIBUTAÇÃO DA TRANSFERÊNCIA FINANCEIRA NAS OPERAÇÕES COMERCIAIS: UMA ALTERNATIVA TÉCNICA PARA SUBSTITUIÇÃO DOS IMPOSTOS DE CONSUMO
}

\author{
MÁRIO JoRge P. C. LIMA
}

Professor Adjunto da Faculdade de Direito da UFBA, Doutor em Direito/UFPE.

\section{Resumo}

O desenvolvimento do comércio convencional ou eletrônico se expande em todo o mundo e requer a harmonização dos ordenamentos jurídicos dos países, sobretudo dos sistemas fiscais nacionais, que representam uma das barreiras mais resistentes à integração dos negócios. Os tributos de maior impacto sobre as transaçóes comerciais convencionais ou eletrônicas são os impostos de consumo e sobre vendas. As transações comerciais significativas atuais são dependentes dos meios eletrônicos seja para registro ou realização de transferências financeiras. As transaçôes comerciais são negócios que operam em dois sentidos contrapostos, num deles, o fornecedor de mercadoria ou bem cumpre a obrigação de entrega do objeto material transacionado, e no outro, o adquirente cumpre a obrigação de transferir ao fornecedor uma quantia pecuniária correspondente ao valor econômico da transação. São duas faces diferentes do mesmo objeto, inarredável e intrinsecamente vinculadas. $\mathrm{O}$ artigo discute a maior vantagem da incidência da tributação sobre a transferência financeira contida nas transações comerciais, ao invés do recolhimento de impostos de consumo ou sobre vendas recolhidos ao longo da cadeia de circulação comercial.

\section{Palavras-chave}

Comércio transnacional; Tributação; Transferência financeira.

\section{Resumen}

El desarrollo del comercio convencional o electrónico se expande en todo el mundo y requiere la armonización de los sistemas jurídicos de los países, especialmente de los sistemas nacionales de impuestos, que representan una de las barreras más fuertes a la integración de los negocios. Los impuestos con mayor impacto en las transacciones comerciales convencionales o electrónicos son los impuestos al consumo y sobre las ventas. Las transacciones comerciales significativas actuales son dependientes de los medios electrónicos para registrar o hacer transferencias financieras. Las transacciones comerciales 
son negocios que operan en dos direcciones opuestas, uno de ellos, el proveedor de bienes o servicios cumple con la obligación de entregar el objeto material comercializado, y por otro, el adquirente cumple la obligación de transferir al proveedor un importe en efectivo correspondiente al valor económico de la transacción. Son dos rostros diferentes del mismo objeto, inquebrantables e intrínsecamente vinculados. El artículo aborda la mayor ventaja de la incidencia de los impuestos sobre la transferencia financiera contenida en las transacciones comerciales, en lugar de la recaudación de los impuestos al consumo o sobre las ventas recogidos a lo largo de la cadena de circulación comercial.

\section{Palabras clave}

Comercio transnacional; Impuestos; Transferencia financiera.

\section{Introdução}

A abordagem de temas tributários não é confortável para a atividade empresarial porque a tributação sempre se constitui um custo indesejável para empresas e cidadãos e os procedimentos de coleta de impostos demandam burocracia e tarefas adicionais para as equipes de gestão. No entanto, as taxas e impostos são uma realidade incontornável no mundo dos negócios e a ferramenta habitual de empresários e gestores na lida com os tributos é o planejamento, para reduzir sua influência nefasta sobre os preços e os lucros.

Por outro lado, os impostos também são uma necessidade no mundo livre, como se constata nas palavras do Juiz Holmes: "Taxes are what we pay for civilized society" (Oliver $\&$ Peel, 1996), e, embora alguns economistas liberais enxerguem os impostos como limites à liberdade, para outros, os tributos constituem o preço da liberdade (Torres, 1991).

Em verdade, o estado fiscal tem sido uma característica do estado moderno (Nabals, 2004) até a contemporaneidade, e portanto, dependente da tributaçáo para suprir a demanda pública, e não há, por enquanto, melhor estrutura política para garantir a liberdade social.

\section{O Impacto dos Sistemas Fiscais sobre Transações Comerciais}

Os sistemas fiscais nacionais são objeto de necessária compreensão nas atividades cotidianas das empresas, e quando isso significa a travessia de negócios sobre as linhas de fronteira de territórios, a diversidade dos sistemas torna-se um grande desafio. Antes de tudo, as diferenças e alteraçóes dos regimes fiscais nacionais não se constituem em problema passível de solução pela agilidade do poder corporativo, mas consistem em obstáculo

1 Impostos são o que pagamos para ter uma sociedade civilizada (tradução do autor) 
a ser enfrentado por equipes de governo, sempre mais lentas que o desejável e limitadas pelas circunstâncias das políticas públicas.

Tributos significam transferência de riqueza privada para a disponibilidade dos governos, e isso se justifica para satisfaçáo das demandas públicas. Por isso, os impostos podem ser extraídos apenas quando existe riqueza, e os negócios são atividades que mantêm e aumentam a riqueza. Os sistemas fiscais nacionais contemporâneos são implementados sobre a extensão geográfica de sua competência jurisdicional, isto é, imputavéis sobre o espaço e as pessoas alcançáveis para a coleta de impostos. No entanto, os métodos e as fontes de tributação ao longo da história têm mudado em acompanhamento da dinamica econômica.

A mudança de métodos e fontes de tributação segue a mudança na capacidade dos fatos econômicos para expressar riqueza tributável dentro economias nacionais. Isso significa que, quando uma nova atividade ou operação econômica emerge com mais riqueza latente, o sistema de tributação estende demanda para incluí-la na sua abrangência para aumentar a base tributária. Em paralelo, as fontes econômicas antigas perdem o seu potencial de riqueza e o Estado necessita de novas fontes de receita para seu sustento. Nesse sentido, outrora, durante o predomínio de economia agrária, a tributação era dirigida sobre as propriedades de terra e sua produção. Mais tarde, com o desenvolvimento do comércio, a tributação se redirecionou progressivamente para o rendimento da circulação de mercadorias.

Desde o final do século 20, o movimento de globalização tem se consolidado e seu efeito principal tem sido a aceleração do comércio em todo o mundo, no objetivo de reunir as naçóes e ampliar o desfrute geral da riqueza assim produzida. Em adendo, o incremento dos métodos de negócios eletrônicos têm se consituído em modalidade das mais eficazes para a dinâmica da globalização. Essas operaçôes comerciais através de meio eletrônico são oportunas e conhecidas sob a denominação consagrada de e-commerce ou e-business.

No entanto, ambas as modaliddes de transaçóes de comércio, seja convencional ou eletronica (e-commerce), enfrentam seguidos obstáculos, mesmo dentro de um único país, como aconteceu e acontece na federação estadunidense com suas várias regras de membros federativos. Essas dificuldades aumentam, quando se trata de negócios entre naçôes com sistemas fiscais díspares.

O mecanismo que pode reduzir a obstrução de impostos para as transaçóes comerciais globais é a harmonização dos sistemas fiscais, como a Comunidade Europeia desenvolve entre seus membros, mas, mesmo assim, para a atividade comercial em geral, o melhor modelo fiscal consiste naquele que mais facilita o livre comércio, ou seja, abolição total dos impostos incidentes, mas isso é impossível. Portanto, a maneira mais próxima de 
se reduzir os obstáculos fiscais é o uso de apenas um único imposto geral cobrado em cada operação comercial, removendo quaisquer outros obstáculos fiscais.

O primeiro passo para tentar a harmonia fiscal é a análise dos vários tipos de impostos em vigor, dentro das naçóes, para observar aqueles que impedem a agilidade para o livre comércio, e as tendências na cena da tributação global.

\section{As Modalidades Atuais De Impostos}

Uma das classificações mais aplicadas às espécies de impostos os subdivide em dois tipos, com fundamento no critério do contribuinte efetivamente onerado com o encargo: os impostos diretos e os impostos indiretos (Freeland, et al, 2000). Imposto Direto é exigido de quem deve pagá-lo e Imposto Indireto é um imposto pago por alguém que pretende transferir o ônus para outra pessoa, geralmente, por inclusão no preço de venda. Portanto, o imposto de renda é um "imposto direto", porque é recolhido pelo próprio contribuinte, conforme a lei, que consiste no verdadeiro onerado do encargo. Por sua vez, os impostos sobre consumo são modalidades de "imposto indireto", porque o responsável pelo recolhimento é o fornecedor da mercadoria ou serviço, mas o verdadeiro onerado com o encargo é o consumidor final.

Nessa classificação, resta evidenciado que incidem impostos indiretos sobre as operaçóes comerciais, porque esses são adequados para oneraçáo de riqueza produzida através da dinâmica econômica, enquanto os impostos diretos são adequados para oneração da riqueza estática. Atualmente, as naçóes usam ambos os tipos de impostos para arrecadar fundos dos cidadãos e das empresas para sustento das despesas dos governos.

Nessa estrutura, o imposto de renda é o mais conhecido dos impostos. Este tipo de imposto geralmente visa a receita auferida pelo contribuinte, cidadão ou empresa, em um período fiscal de um ano em geral. Esse imposto admite conceitos diversos para rendimentos e receitas de país para país. Além disso, os sistemas de imposto de renda usam métodos diferentes para avaliar indivíduos e empresas quanto a riqueza, ganhos, receitas, custos e lucros, exigindo estrutura de contabilidade complexa para extrair o imposto devido por agentes privados. Esse imposto, em verdade, não afeta diretamente as operaçóes de comércio.

Os tributos sobre propriedades ou sobre imoveis são antigos impostos normalmente cobrados sobre a propriedade de bens imóveis ou outros bens, onde o proprietário de uma parcela do bem se torna obrigado a pagar esse imposto anualmente. Empresas e cidadáos são afetados por esses impostos, que não afetam as transaçóes comerciais comuns.

Existem também os impostos sobre a transferência de patrimonios por herança que é cobrada sobre a mudança de proprietário de bens ou mercadorias, cidadãos ou empresas, na sucessáo por morte, que também não afetam diretamente as operaçóes comerciais. 
Impostos alfandegários incidem sobre o comércio de fronteira entre as naçóes, e são de excepcional interesse para o comércio mundial. Através desses impostos, as naçóes protegem seus mercados internos e sistemas de produção contra as mercadorias estrangeiras.

A dinâmica de negócios costuma ser onerada por impostos sobre o consumo ou sobre vendas. Esses dois tipos de impostos atuam sobre o preço de transferência das mercadorias vendidas ou sobre o preço do serviço que foi dado, ou mesmo a soma dos bens e serviços, quando vendidos em conjunto. $\mathrm{O}$ imposto sobre vendas é normalmente exigido apenas uma vez na venda final ao consumidor definitivo e o imposto sobre o consumo é geralmente repassado em cada operação, ao longo da circulação da mercadoria. No Brasil, são exemplos de imposto de consumo, o ICMS, e na Europa, o IVA, imposto sobre o valor agregado, ou VAT.

No Brasil existe ainda um imposto sobre as operaçóes financeiras cobrado sobre investimentos financeiros, empréstimos, câmbio, seguros, aquisição de títulos mobiliários e outros negócios bancários.

Nas modalidades de impostos mencionadas, observa-se que os mesmos induzem impactos diferentes sobre operações comerciais, onde os impostos mais incidentes são os impostos alfandegários e os de consumo ou vendas. Por isso, a redução do impacto desses impostos nas transaçóes comerciais deve ser o maior objetivo das naçóes para facilitar e incrementar seus negócios e aumentar suas riquezas potenciais.

\section{Uma Especulação sobre o Futuro dos Impostos}

No passado, a riqueza se estabelecia em termos locais e sobre propriedades e patrimonios, por isso, a imposiçáo de tributos sobre esse tipo de riqueza predominava. Mais tarde, na dinâmica da sociedade industrial, a atividade econômica foi compartilhada em várias etapas de produção e circulação e a tributação se estendeu sobre receitas de vendas de operaçóes comerciais. Em paralelo, o comércio atingiu mercados de longa distância e as barreiras fiscais aduaneiras se tornaram modalidade adequada de tributação.

Atualmente, uma das principais características da riqueza é a mobilidade em termos mundiais. A maior parte da riqueza está expressa em títulos negociáveis, como açóes, certificados de créditos e ativos em moeda, constantemente transferidos através de meios de comunicação eletrônicos. Dessa forma, há de se deduzir o progressivo avanço da tributação incidente sobre essas transaçóes eletronicas de riqueza.

Existem algumas propostas e experiências de taxação dessa circulação eletronica de riqueza. A mais conhecida delas é a Tobin Tax, do economista James Tobin, que a concebeu com objetivo de controle da volatilidade causada pelas transferências internacionais abruptas de fundos financeiros, e que ainda induz benefícios adicionais como o auxílio à 
repressão sobre corrupção, terrorismo e traficos ilícitos em geral e receita adicional para as naçôes enfrentarem suas demandas públicas sociais. A Taxa Tobin consiste na aplicação de uma alíquota percentual incidente sobre a transferência financeira além fronteiras, e seria recolhida pelo país do qual o ativo se retirou. A experiência foi tentada na Suécia entre 1984 a 1990 sem sucesso.

$\mathrm{Na}$ atualidade, a riqueza mobiliária e sua circulação se tornam predominantes, e outras idéias, além da Taxa Tobin, surgem no intuito de atingir fatos econômicos dessa riqueza ou melhor distribuir a tributação sobre seu montante agregado, a exemplo da proposta do imposto sobre lucros unitários aplicável a corporaçôes transnacionais (Mold, 2004), que sugere uma análise contábil para determinar onde são obtidas as receitas e os lucros das corporaçóes, e repartir a tributação de acordo com a origem local das receitas ou capital fixo, para melhor distribuir a arrecadação em favor de países em desenvolvimento.

No entanto, a discussão proposta não se refere ao implemento da Tobin Tax, mas a tributação de transações comerciais com incidência do imposto sobre a operação financeira contraposta à efetiva operação de transferência do bem ou serviço. Observe-se que os impostos de consumo existentes costumam incidir sobre as sucessivas operaçóes nas cadeias produtivas e de circulação comercial, contudo, a incidência da tributação na operação contraposta de transferência financeira se revela mais vantajosa porque facilita a prática, a certeza e o alívio da economia produtiva, através da redução dos custos de gestão e circulação.

O Brasil manteve entre os anos de 1997 e 2007 um imposto sobre movimentação financeira, a CPMF - Contribuição Provisória sobre Movimentação Financeira. O imposto era odiado por todos, sejam empresas ou indivíduos, sejam economistas ou advogados, que denunciavam a sobrecarga da exigência desse imposto, concomitante com a exigência dos demais impostos tradicionais incidentes nas mesmas transaçóes.

A tendência de impor tributos de algum tipo sobre operaçóes financeiras vem se consolidando, como se constata do projeto da Comissão Européia de implantar um imposto sobre transações financeiras (FTT - financial-transaction tax) a partir de 2016, postergado da previsão inicial para 2014, que incidirá sobre transaçóes com títulos mobiliários e derivativos do mercado financeiro. Nesse objetivo, a França, desde 2012, e a Itália, desde 2013, estabeleceram impostos sobre transaçôes com títulos mobiliários (The Economist, 2015).

\section{Peculiaridades do Comércio Eletrônico}

O movimento da globalização incrementado pelo meio eletronico encurta as dimensóes de tempo e espaço. $\mathrm{Na}$ dimensão espaço esse movimento significa a interligação entre novos lugares, novos mercados e novas oportunidades de negócios. $\mathrm{Na}$ dimensão 
tempo, o meio eletrônico permite maior agilidade na realização dos negócios. Enquanto isso, permanecem algumas barreiras tradicionais de espaço e ritmo para o comércio eletronico (e-commerce) que representam problemas ainda pendentes para empresas, além do surgimento de outros problemas típicos dessa modalidade de operação em expansão.

Os problemas que permanecem, em geral, resultam da nova forma de resolver velhas questóes, tais como a entrega, os contratos, a proteçáo dos consumidores, a privacidade de negócio, arbitragem, registros locais, ativos intangíveis, marca, etc. Entre essas velhas questôes estão a diversidade de leis, práticas de comércio e procedimentos aduaneiros, decorrentes de sistemas nacionais diferentes.

Os novos problemas trazidos pela tecnologia são: a pirataria, a segurança de transações eletrônicas, transferências instantâneas de fundos, seleção de informaçóes, etc. Outras decorrem das estruturas físicas, como a demanda de energia, linhas de comunicação e padronização de equipamentos. A arrecadação de impostos também pode se tornar um novo problema através de evasão fiscal eletrônica.

A conjunção dos problemas antigos com os problemas novos vem sendo enfrentada por equipes especializadas, mas, desde o início, o e-commerce enfrenta a diversidade de regras locais, porque costuma ser tratado ao modo do comércio convencional dentro dos contornos territoriais das fronteiras e da jurisdição fiscal dos Estados. Por enquanto, um regulamento unificado completo para o e-commerce parece um sonho impossível.

A rota mais pragmática para desenvolver o e-commerce consiste na equiparação dos tributos incidentes nas operaçóes de comércio convencionais e eletrônicos, como recomenda a OCDE (VAT/GST Guidelines, 2014) e a harmonização dos sistemas de impostos nacionais em relação à demanda da dinâmica eletrônica, ou, pelo menos, ajustar os procedimentos de arrecadação à velocidade e demandas de e-commerce.

Nesse sentido, o consenso sobre a tributação do comércio eletrônico segue os princípios da OCDE (VAT/GST Guidelines, 2014) para manter a equiparação para com a tributação aplicada para o comércio convencional, no que diz respeito a: - Neutralidade, para manter a paridade com a tributação aplicada a negócios similares do comércio convencional; - Eficiência, para reduzir ao mínimo o custo dos procedimentos; - Certeza, pela aplicação de normas claras; - Arrecadação justa, para recolher apenas o necessário e não incentivar fraudes; - Flexibilidade, para adaptação às novas tecnologias.

Quanto à tributação do uso da internet, prevalece ainda a iniciativa estadunidense de manter essas operaçôes livre de impostos (Internet Tax Freedom Act, 1998).

\section{As Tentativas de Harmonização dos Sistemas Fiscais}

A harmonização dos sistemas fiscais tem início pela tentativa de unificar todos os impostos incidentes sobre uma única operação de comércio. Além disso, devem ser 
padronizados também os procedimentos, etapas e alíquotas aplicáveis, mesmo quando há apenas um imposto sobre a transaçáo.

Nesse sentido, cabe recordar a política fiscal de harmonização européia, que impede aos membros aplicar tributação diferente para produtos nacionais e de outros membros. Esta regra básica atua para a integração económica, contribuindo para o principal objetivo do Tratado CE, de promover as quatro liberdades: movimento de mercadorias, pessoas, serviços e capitais (Farmer \& Lyal, 1994). A manutenção das quatro liberdades obriga a harmonizaçáo dos sistemas fiscais e regras de comércio, e também de direitos trabalhistas, seguridade social e proteção do consumidor.

A incidência do IVA sobre a circulação de bens e serviços entre os membros da CE se desenvolveu nas últimas décadas com aplicação do método da tributação pelo - sistema de origem - onde o imposto é devido no país fornecedor da mercadoria, mas, recentemente se transformou para a aplicação do método do - sistema de destino - onde o imposto é devido no país adquirente (Lall, 2014), considerado como mais adequado ao regime de mercado unificado. Ambos os métodos induzem a tributação em cada etapa da circulaçáo do produto e cada país membro pode cobrar o IVA sobre as operaçôes de bens ocorridas dentro de seu território, com abatimento da parcela de IVA paga na operação anterior. Portanto, cada membro recebe parte do valor total do IVA, até o consumidor definitivo.

Nos EUA, o sistema fiscal contém um emaranhado de impostos interestaduais e locais sobre vendas e de consumo vigentes no país, que possui inúmeras jurisdiçóes locais qualificadas para recolher os impostos. A iniciativa de harmonização mais importante consistiu no implemento, em 2005, do SSUTA - Streamlined Sales and Use Tax Agreement, que intenta a simplificação e padronização dos impostos estaduais e locais através das premissas de gestão centralizada na administração estadual, uniformidade das bases de impostos locais, padronização e simplificação de alíquotas, e unformização de alíquotas para vendas internas e externas aos estados (Maguire, 2013). Em transaçóes do e-commerce dentro dos EUA são exigidos somente os impostos federais incidentes nos negócios convencionais.

Em regra geral para os impostos de consumo, cabe orientar-se pela diretriz de neutralidade da OCDE (VAT/GST Guidelines, 2014), para que, na aplicação desses impostos, a carga tributária seja suportada no total pelo consumidor final, sem que restos remanescentes sejam onerados aos intermediários da cadeia produtiva ou de circulaçáo comercial.

\section{A Alternativa da Tributação da Transferência Financeira}

A globalização induz a necessidade de reformulação do pensamento jurídico, evoluindo da antiga análise fundada unicamente no direito nacional para abordagens 
multifacetadas, enfatizando a influência de sistemas jurídicos multi-culturais, incluindo a tentativa de harmonização dos sistemas fiscais.

A essência da tributação consiste na escolha de alguns fatos econômicos onde a riqueza se revela notória, e impor um tributo sobre a mesma. Assim, ao longo da história da tributação, foram escolhidos: comércio, propriedade imobiliária, as receitas, os lucros, o consumo, a transferência de propriedade, transposição de mercadorias nas fronteiras, etc. Atualmente, alguns desses fatos econômicos não são mais adequados com a nova riqueza econômica dinâmica e em outros, a tributação já atingiu a máxima incidência possível.

A tributação aduaneira, por exemplo, tende a ser padronizada e realizada apenas com o intuito de regulamentação, a tributação sobre propriedade imobiliária tem importância apenas para os governos locais, bem como as taxas sobre a transferência de propriedades e heranças.

O imposto sobre a renda e os impostos sobre o consumo ou vendas, são as principais fontes de receitas dos países, e ao mesmo tempo são os impostos mais influentes nos negócios contemporâneos.

O imposto de renda é considerado imposto dos mais adequados porque se admite que alcança a maior amplitude de riqueza da maneira mais justa. Esse imposto não incorre diretamente sobre a operaçóes de comércio e permite dedução de gastos com outros tributos e obrigaçóes. Assim, o imposto de renda alcança toda a gestão corporativa, mas, em regra, não prejudica a atividade cotidiana, com incidência em cada transacção.

Os impostos sobre o consumo incorrem sobre cada operação e, para o comércio convencional ou e-commerce, sua imputação consiste em obstáculo de desejável remoção. Quanto a esses impostos sobre o consumo, é importante observar o procedimento técnico de tributação em cada operação comercial.

O núcleo da transação de comércio consiste na compra de mercadorias ou prestação de serviços, com a entrega do produto ao adquirente, em operação que se direciona no sentido - do fornecedor para o adquirente -, segundo os princípios da autonomia privada e livre contrato. Todavia, a transação comercial induz uma outra operação vinculada, que consiste justamente na transferência financeira, direcionada no sentido - do adquirente para o fornecedor -, contraposta à operação de fornecimento.

Por sua vez, a tributação sobre transaçóes comerciais é um efeito externo imputado pela lei. Isso significa que a tributação não depende da vontade dos atores privados, mas é promulgada pelo poder do governo sobre a riqueza econômica que a transaçáo expressa.

O pagamento com dinheiro, padrão monetário, ou a compensação com a transferência de fundos, substituiu a troca simples, ao longo da história da integração dos negócios, primeiro através de produtos com aceitação confiável, em seguida, a troca metálica, 
seguida da moeda metálica padrão, e finalmente o papel-moeda. Na atualidade, consolida-se o predomínio dos arquivos eletrônicos e cartóes magnéticos, com suas transferências eletrônicas, e no futuro, presume-se a disseminação do Bitcoin ${ }^{2}$.

No mundo dos negócios atual é impossível pensar em qualquer retorno sobre os passos anteriores dessa evolução, e até mesmo o recente papel-moeda e o padrão-ouro estão prestes a ser abandonados. Não há viabilidade nem mesmo para imprimir em papel todo o dinheiro do mundo contabilizados em arquivos eletrônicos. Assim, os negócios atuais são gradualmente dependentes dos meios magnéticos e eletrônicos e a transferência financeira por esses meios, vinculada às transaçóes comerciais se revela inarredável.

Duas operações são mutuamente contrapostas na transação de comércio: de um lado, a entrega da mercadoria ou serviço, do outro lado, uma transferência financeira. Esses são os dois lados da mesma moeda, e representam exatamente a mesma quantidade econômica, expressa em padrão monetário.

Observe-se que as duas operaçóes se compensam no âmbito da transação comercial, a entrega mercadoria/serviço contra a transferência financeira porque são expressóes da mesma riqueza, portanto, revela-se indiferente a incidência dos impostos sobre um lado ou o outro lado da transação. Assim, a cobrança de impostos sobre o lado da operação de transferência financeira, isto é, o pagamento do adquirente ao fornecedor, traz o mesmo efeito da tributaçáo no outro lado, a operação de entrega mercadoria/serviço, do fornecedor ao adquirente.

Em regra, a incidência dos impostos sobre o consumo ou sobre vendas ocorre na operação de entrega mercadoria ou serviço, quando o fornecedor se encarrega da cobrança de impostos, através de sua inclusão no preço de venda e o posterior recolhimento ao governo. Por isso, os impostos sobre o consumo ou vendas podem ser substituídos, com vantagem, pela tributação sobre a operação de transferência financeira, mais prática para coletar e pagar. A taxa a ser aplicada no lado de transferência financeira pode ser estimada sobre o movimento total de fundos no mercado financeiro, para produzir a mesma quantidade de receitas obtidas com os impostos sobre o consumo ou sobre vendas. Em contrapartida, os impostos de consumo ou sobre vendas seriam abolidos e a tributação sobre transferências financeiras, coletadas de cada contribuinte, deduzidas no imposto de renda.

A tributação sobre o lado de transferência financeira preenche melhor os requisitos da boa tributação segundo os canônes liberais (Smith, 2001): 1 - contribuição proporcional à capacidade econômica do contribuinte sob a proteção do Estado; 2 - o imposto deve ser certo e náo arbitrário, de forma clara e simples quanto ao momento, à maneira e o

2 Bitcoin (BTC) - sistema de pagamentos online por meio de criptomoeda independente de autoridade central, concebido em 2008, operada em rede peer-to-peer, P2P 
montante; 3 - O imposto deve ser exigido no momento ou na maneira mais conveniente para o contribuinte; e 4 - o imposto deve ser planejado para retirar a quantidade mínima possível da receita privada, em favor do erário público.

A tributação sobre a operação de transferência financeira cumpre melhor esses requisitos porque: 1 - A incidência opera em proporção com o montante dos fundos transferidos, por isso, quem movimenta mais dinheiro, paga mais impostos. A tributação sobre o consumo, também funciona assim, porque consumidor é o verdadeiro contribuinte final; 2 - A tributação é determinada por taxa fixa imposta na transferência financeira e o momento do recolhimento é a operação da efetiva transferência; 3 - Existe maior conveniência para o contribuinte, porque ele vai pagar apenas quando adquirir, e o procedimento é o melhor, porque o contribuinte não assume qualquer tarefa de pagar. O banco irá controlar a arrecadação de impostos e da retenção de informaçóes para o governo e o cidadão. 4 - A tributação pode ser tão leve quanto os países desejarem. Os acordos internacionais costumam estipular uma faixa para a taxa máxima e mínima, onde a arrecadação pode ser aumentada ou diminuída temporariamente.

Para as modernas exigências: eficiência, equidade e eficácia (Wachtel, 1998), a tributação da transferência financeira também é mais adequada. A eficiência é obtida pela extração eletrônica automática, a equidade pode ser alcançada por faixa variável de taxas e a eficácia é mais garantida pelo menor potencial de evasão fiscal. Assim, a política fiscal e os custos de gestão das empresas são aliviados pela substituição dos impostos de consumo ou de venda pela tributação sobre a transferência financeira, induzindo aos negócios em geral, livres de procedimentos da cobrança tributária, maior estímulo para desenvolvimento e integração.

O desoneração de impostos sobre economia produtiva, incluído o e-commerce, pode promover alteraçóes significativas sobre custos e iniciativas de comércio, alterando todo o pensamento negocial desenvolvido desde que o sistema fiscal moderno se iniciou há três ou quatro séculos atrás. O e-commerce seria ainda mais estimulado na medida em que o comercio convencional também se acelere com as transferências eletrônicas, ambos descarregados de impostos indutores de improdutividade.

O principal problema poderia ser o sigilo bancário e o acesso do governo na privacidade dos fundos financeiros. Mas, essa questão há de ser comparada com a vantagem do maior controle sobre o financiamento de atividades ilícitas internacionais, como terrorismo e tráficos clandestinos, bem como o controle da evasáo de receitas tributáveis para paraísos fiscais.

Por sua vez, o controle da movimentação financeira não demanda o acesso imediato e direto sobre os arquivos financeiros individuais, mas apenas a verificação comparativa entre o volume das transações financeiras e o valor do imposto recolhido. O contribuinte 
mantém a privacidade de seus ativos e o controle sobre a movimentação e a quantidade de imposto extraído de seus fundos. O banco precisa apenas transferir o registro eletrônico de cobrança de impostos para a conta do governo, e manter a lista de quantidades enviadas. Os bancos podem ser pagos pelo serviço.

Outro problema é o destino das receitas dos impostos de consumo ou sobre vendas, geralmente, recolhidos pelos governos nacionais e locais. $\mathrm{O}$ regime de tributação substituto sobre transferência financeira deve assistir às mesmas entidades locais ou países, e podem ser distribuídos entre os endereços de filiais dos sucessivos adquirentes da mercadoria ou serviço, atentando para a peculiaridade do comércio eletrônico, que induz dificudade de tributação quando a transação é independente da existência de um estabelecimento físico na jurisdição fiscal atingida (Bacchetta, et al, 1998).

O controle econômico de transferência financeira se estabelece no início por uma taxa ínfima e compensável dos impostos de consumo ainda incidentes, e depois progressivamente aumentada até a substituição dos mesmos. A estipulação de taxas ou faixas da taxas pode ser determinada por meio de acordos internacionais, com equilíbrio controlado através de métodos econômicos de estimativa, como a Curva de Laffer (Gambiagi \& Além, 2001) ou a Otimalidade de Pareto (Stephen, 1993), usados em estudos de Direito e Economia para tributação. Esse controle será permanente para as equipes econômicas do governo, mas será apenas mais uma tarefa de controle fiscal, dentro dos gigantescos sistemas manejados por equipes econômicas e financeiras de governo, que devem absorver, com vantagem, os atuais sistemas de controle da arrecadação sobre consumo ou vendas.

\section{Conclusões}

1 - O desenvolvimento do comércio convencional e eletrônico através do mundo demanda a harmonização dos sistemas legais nacionais e sobretudo a padronização dos sistemas fiscais nacionais. Liberdade fiscal completa é inviável. Unidade fiscal também não é fácil, por causa dos diversos tipos de impostos de consumo e sobre vendas arrecadados em numerosos territórios locais e de países.

2 - As espécies de tributos mais prejudiciais para o comércio convencional e e-commerce são os impostos de consumo ou sobre vendas, uma vez que os demais tributos que afetam a dinâmica dos negócios não incidem em cada operação comercial.

3 - A mobilidade da riqueza é uma característica notável dos negócios atuais e sugere a mudança nos métodos de tributação tradicionais para manter a base tributária e as receitas dos governos. Os sistemas de tributação não são diferentes para e-commerce ou comércio convencional, por isso, os impostos de consumo e sobre vendas significam os mesmos obstáculos para o comércio convencional ou e-commerce. A ferramenta eletrônica tem se expandido em todos os negócios, mas é especialmente essencial em operaçóes 
financeiras, onde os arquivos magnéticos e eletrônicos mantêm o registro para todas as contas de fundos e transferências.

4 - As transações de comércio convencionais e de e-commerce induzem operação de transferência financeira vinculada e estão sujeitas a tributação imposta por leis. $\mathrm{Na}$ operação comercial, um dos lados da operação é a entrega de mercadorias ou serviços, enquanto, do outro lado, a operação é a transferência financeira. As duas operaçôes atuam lado a lado na transação comercial que realiza o escambo de obrigaçóes entre os contratantes. Assim, a tributação no lado da operação de produção e fornecimento da mercadoria / serviço tem o mesmo efeito da tributação no lado da operação de transferência financeira. Entretanto, a tributação sobre a transferência financeira demanda somente procedimentos automáticos, operados em meio eletrônico, enquanto que a tributação da operação de transferência da mercadoria / serviço demanda aparato complexo e custoso para o recolhimento dos impostos de consumo e sobre vendas, onerando os esforços da economia produtiva. Assim, os impostos de consumo e sobre vendas podem ser substituídos, com vantagem, pela tributação sobre a transferência financeira vinculada à transação comercial.

\section{Referências}

BACCHETTA, M, LOW, P, MATOO, A, SCHUKNECHT, L, WANGERAND. H, WEHRENS, M Electronic Commerce and the role of the WTO, WTO,1998. Disponível em:<www.wto.org > acesso em maio/2015.

FARMER, Paul, LYAL, Richard, European Community Tax Law, Claredon, Oxford, 1994.

FREELAND, J J, LATHROPE, D J, LIND, S A and STEPHENS, R B, Fundamentals Federal Income - Case and Materials, New York, University Casebook Series:Foundation Press, 2000.

GAMBIAGI, Fábio, ALÉM, Ana Cláudia. Finanças Públicas: teoria e prática no Brasil, Rio de Janeiro, 2a ed, Editora Campus, 2001.

LALL, Tarlochan, The definitive VAT system - Better the devil you know? 2014. Disponível em:< www.lexisnexis.co.uk/en-uk/products/pslfreetrial.page>, acesso em maio/2015.

MAGUIRE, Steven, State Taxation of Internet Transactions, Congressional Research Service, 2013. Disponível em:<www.fas.org/sgp/crs/misc/R41853>, acesso em maio/2015.

MOLD, Andrew, A proposal for unitary taxes on the profits of transnational corporations, CEPAL Review, 82, p. 37-53, 2004. Disponível em:<www.cepal.org/en/ publications/11008> acesso em maio/2015. 
NABALS, José Casalta, O Dever Fundamental de Pagar Impostos, Coimbra, Almedina, 2004.

OECD, International VAT/GST Guidelines, 2014. Disponível em:<www.oecd.org/ctp/ $\rightarrow$ acesso em maio/2015.

OLIVER, Philip D, PEEL Jr, Fred W, Tax Policy - Readings and Materials, Westbury, NY, University Case Books, Foundation Press, 1996.

SMITH, Adam, Riqueza das Naçóes (trad. Norberto de Paula Lima), Curitiba, Hemus, 2001.

STEPHEN, Frank H., Teoria Econômica do Direito (trad. Neusa Vitale), São Paulo, Editora McGraw Hill, 1993.

THE ECONOMIST, V 414 N 8923, Still kicking, p.57-58, London, Jan, $31^{\text {st }}$ - Feb, $6^{\text {th }}, 2015$.

TORRES, Ricardo Lobo, A Idéia de Liberdade no Estado Patrimonial e no Estado Fiscal, Rio de Janeiro, Renovar, 1991.

WACHTEL,Howard M,The Mosaic of Global Taxes, in Global futures:shaping globalization Zed Books, 2000, p. 83-97. Disponível em:<www.globalpolicy.org/finance/ currtax/ ->, acesso em julho/2004. 